\title{
The relevance of Kaizen-based work-readiness training for South African University of Technology students
}

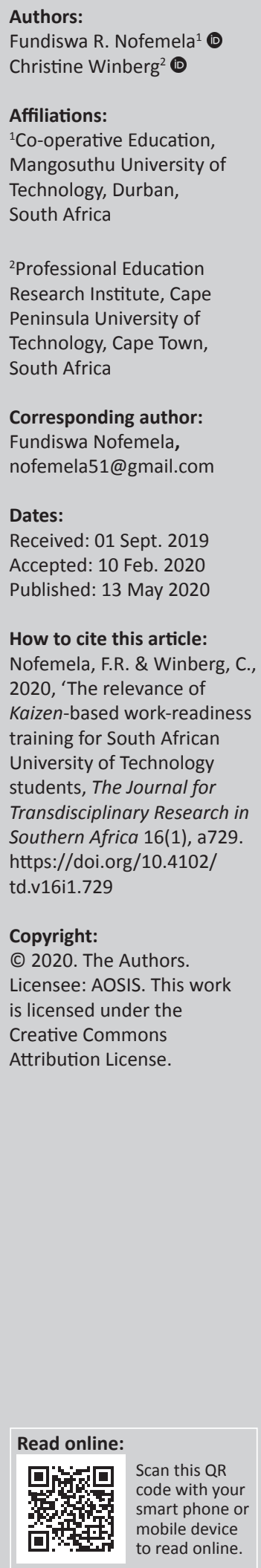

Kaizen-based work-readiness training originated in Japan and is based on the 'lean' production methods taught in Toyota factories in Japan and abroad. Kaizen-based training is rooted in the Kaizen principles of respect for others, the elimination of waste, continuous improvement, collaboration as the key to productivity and innovation as incremental in work processes. The Employability Improvement Programme (EIP), an initiative between the South African Department of Higher Education and Training, the Japan International Cooperation Agency and South African Universities of Technology, is a Kaizen-based short training programme that was introduced in 2011 with the intention to enhance South African University of Technology students' work-readiness. The research question guiding the study is: how could a short Kaizen-based intervention contribute to South African University of Technology students' work-readiness? The data for the study comprise curriculum documents, teaching and learning media, video footage and interviews with participants of the Kaizen events over the period 2016-2018. The study found that the EIP supported students' acquisition of interpersonal skills and personal dispositions towards work-readiness, but skills that were related to workplace relations in context, professional values and a sense of a broader contribution to society were largely absent. The study recommends that longer term, more integrated and better contextualised forms of training are necessary in attaining work-readiness in the complex South African work context.

Keywords: Kaizen; lean education; work-readiness; universities of technology; vocational training.

\section{Introduction}

Graduate unemployment is a concern for higher education internationally (Chan 2015; Tomlinson 2017) and also in South Africa (Kraak 2015; Van Broekhuizen 2016). It is a particular concern for the Universities of Technology as most of the programmes offered are diploma-level qualifications that prepare students for direct entry into labour markets, supported by practice-oriented curricula, internships and other forms of work-integrated learning. Diploma programmes educate technicians, technologists and practitioners whose skills contribute to developing economies. Although most qualifications are designed for specific professions or occupations, and are accredited by professional bodies, there is a need to improve students' work-readiness in order to facilitate students' transition into the world of work (Ahmad, Zainal \& Rahmat 2012). In the past, and particularly because of the work experience obtained through the consistent practice of cooperative education, $60 \%$ of University of Technology graduates had secured employment in their field on graduation (Moleke 2005). This trend has reversed, and many Universities of Technology students currently struggle to find appropriate employment in the fields in which they are qualified. Recent annual graduate surveys conducted at the research sites of this study indicate that, on average, only $40 \%$ of University of Technology graduates had secured employment at the time of graduation (Kraak 2015:100). Of particular concern with regard to the graduate unemployment figures is the reproduction of social inequalities with regard to who gains and who does not gain employment (Fongwa, Marshall \& Case 2018). While there are many factors that affect the employment of graduates, the mismatch between the skills that graduates develop through their university studies and those that employers require from graduates in the 21st century has been highlighted as a contributing factor (Kraak 2015). This skills' mismatch has adversely affected the employment prospects of University of Technology graduates more than other higher education cohorts (Kraak 2015:101-102).

As part of their commitment to student employability, South African Universities of Technology offer a number of work-readiness programmes. The Employability Improvement Programme (EIP), which is the focus of this study, is based on the Kaizen principles of continuous improvement, 
the provision of value or quality at all points of the training process, including eliminating waste, respect for others and innovation as the end point of an iterative process (Alves et al. 2017). The manner in which these Kaizen principles are evaluated in work-readiness training will be demonstrated later in the study. Kaizen-based training, also known as 'Lean Education'; 'Six Sigma'; or 'Conceive, Design, Implement and Operate' (CDIO) (Murman, McManus \& Weigel 2014), was developed in Japan for industry training, most notably at Toyota vehicle assembly plants. These industry-based training programmes for lean manufacture were adapted for work-readiness training at universities (Murman et al. 2014); thus, a programme such as the EIP can be recognised as having similarities with other forms of Kaizen-based training.

The EIP was developed in Japan and its implementation in South Africa is supported by the Japan International Cooperation Agency (JICA) through a bilateral agreement with the South African Department of Higher Education and Training (DHET). The DHET found the EIP training to be suitable for Universities of Technology students in professional and vocational programmes. The EIP is a short campus-based intervention intended to prepare students for the work placements that are part of their formal programmes. The EIP is intended to help South African students develop work-readiness skills, such as time management, project management, understanding the work environment and working in teams. The training programme is offered in two phases: (1) a half-day workshop on the principles of Kaizen as applied to workplaces (such as 'The Seven Wastes' and an orientation towards delivery of quality products at appropriate cost) and (2) two-and-a-half days of hands-on practical training that simulates a truck assembly plant in which students assume various roles that typically exist in workplaces, and receive feedback on their performance. The assembly plant runs are repeated several times to enable students to reflect on and improve their performance, and, in the process, internalise the Kaizen principles.

The contexts for work-readiness training in Japan and South Africa could not be more different. Japan is a highly developed country; its economy is currently ranked as the third largest globally. Currently, the number of people in work in Japan is 66.64 million, the most since comparable data became available in 1953 (Japanese Ministry of Internal Affairs and Communications 2019). In the same time period, the South African economy went into technical recession, with 6.2 million (27\%) of South Africans unemployed and actively seeking work (Statistics South Africa 2019). Several studies have suggested that unemployment figures of $35 \%$ are more probable, given the many South Africans who have given up and are no longer actively seeking formal employment (Van Broekhuizen 2016). Against the background of unemployment and social inequality, it is hardly surprising that labour relations in South African workplaces are complex and challenging, with labour relations linked to low levels of trust between employers and employees (Jordaan \& Cillié 2016).
The EIP represents a considerable investment for Universities of Technology, the DHET and the JICA, not only in terms of financial support but also in terms of the time and commitment to the programme by the Japanese and South African facilitators, participating academic departments, the workplace supervisors who attend the EIP training sessions and provide feedback, and the student participants who enrol for the programme in the hope of enhancing their prospects of finding work in their field. Preparation for the implementation of the EIP at the South African Universities of Technology occurred in 2011 in Japan. The first iteration of the EIP was offered at two Universities of Technology in 2012 and grew annually to include all six South African Universities of Technology, one Comprehensive University and one neighbouring country's institution by 2016. Over the period of implementation, the Japanese facilitators handed over the training to South African facilitators who made various changes to the EIP in line with feedback and institutional needs. Between 2012 and the current time, eight universities, three Japanese facilitators and 11 South African facilitators have been involved in the implementation of the EIP. Over the same period, approximately 3000 students have undergone training and approximately 100 workplace supervisors have participated. In spite of the significant resources invested in the EIP, it has not been evaluated. An evaluation of the EIP is thus timely.

The particular problem that this study addresses is the extent to which the Kaizen-based training intervention might address the skills mismatch (Kraak 2015) and contribute towards students' work-readiness. The research question that guides the study is: how could a short Kaizen-based intervention contribute to South African University of Technology students' work-readiness? The research study addresses this question by applying a research- and theoryinformed instrument to evaluate the EIP.

\section{The research literature on work- readiness training}

This review of the literature addresses key differences between 'employability' and 'work-readiness', provides an overview of work-readiness training in higher education and analyses gaps in the work-readiness literature.

\section{Employability and work-readiness}

It is important to differentiate between 'employability' and 'work-readiness'; employability is about acquiring 'a confluence of understanding, subject-specific and generic social practices (or skills), meta cognition (reflection or strategic thinking) and ... incremental self-theories' (Knight \& Yorke 2003:8), while work-readiness has been more narrowly defined as the 'extent to which graduates are perceived to possess the attitudes and attributes that make them prepared or ready for success in the work environment' (Caballero, Walker \& Fuller-Tyszkiewicz 2011:41-42). In other words, employability includes both the technical knowledge and personal and interpersonal skills required for employment, 
while work-readiness focusses more narrowly on the personal and interpersonal skills valued by employers. Work-readiness can thus be understood as a subset of employability. Work-readiness training is usually offered to students as a short pre-employment programme (Cavanagh et al. 2015), while employability needs to be addressed more consistently across the curriculum as a whole (Knight \& Yorke 2003).

\section{Work-readiness in higher education}

The literature on work-readiness is less extensive than the literature on employability. Work-readiness studies have a particular focus on the qualities that enable a student to obtain employment (Rosenberg, Heimler \& Morote 2012). Personal qualities, problem-solving, decision-making, relationships with others, communication, maturity, health and safety habits as well as commitment to the job are the core competencies of work-readiness (Rosenberg et al. 2012:8-10; Smith \& Krüger 2008:134-135). Stone's (2012) systematic review of the literature on work-readiness studies confirms that communication, self-discipline, time management, interpersonal skills and teamwork, problem-solving skills and a positive work ethic are important generic skills for securing employment (Stone 2012:130-131). There are often the differences between the skills that employers and students (as jobseekers) consider important. For example, in the banking sector, employers value numeracy skills and motivation, whereas graduate jobseekers tend to believe that confidence and leadership skills are important in securing work (Raftopoulos, Coetzee \& Visser 2009). In contexts of socioeconomic challenge, such as South Africa, 'hardiness' (Van Dyk 2015:80) and 'resilience' (Walker et al. 2013:117) have been identified as contributing to work-readiness. The literature addresses work-readiness in a number of different fields from engineering (Murman et al. 2014) to business sciences (Carenys \& Moya 2016) - claiming that graduates require generic transferable personal and interpersonal skills in order to be able to adapt to changing market circumstances and organisational needs.

\section{Gaps in the literature on work-readiness training}

The first gap in the literature on work-readiness is the lack of a knowledge base. The absence of a body of underpinning knowledge for work-readiness is evident in the lack of detail in the studies, and the absence of codified curricula. Workreadiness training could thus be said to be 'knowledge blind' (Maton 2014:3-4). While there is agreement in the literature that personal and interpersonal skills are central to workreadiness, these are non-specific skills. This is the second gap identified in the literature. Many studies produce 'wish lists' of generic skills, without identifying the specific attributes. The 'Work Readiness Scale' (Caballero et al. 2011) identified a range of work-readiness indicators for graduates, but the list of work-readiness factors is not clearly categorised and there is no theoretical support for the indicators. Thus, a third gap is the lack of an educational theory of work-readiness training. Basing educational training on management principles is contentious: while Alves et al. (2017:149) and Murman et al. (2014:220) defended the educational value of 'continuous improvement' and 'elimination of waste', Sears (2003) and Vidal (2007) pointed to the potential pitfalls for student learning in conflating management principles and training principles. The lack of a guiding theory can be seen in the descriptive, rather than the analytic, nature of many studies. Related to the theory gap is the tendency of many authors to uncritically accept Kaizen-based approaches. A fourth weakness identified is the absence of empirical research to support many of the claims on the effectiveness of workreadiness training interventions. Many of the studies of Kaizen-based or lean training are descriptions of interventions that lack a clear research or evaluation process (e.g. Alves et al. 2017; Murman 2017).

The gaps in the literature on work-readiness training that this study intends to address are: (1) the absence of the knowledge base, (2) the non-specificity of work-readiness factors, (3) the lack of educational theory and (4) the missing empirical data.

\section{Theoretical framework: Legitimation code theory}

A gap that was pointed out in the literature reviewed is that much of the literature does not theorise work-readiness training or explain how it might enable or foster the emergence of capable and employable graduates but rather focuses on issues of disciplinary curricula learning (Shay \& Steyn 2015). For this reason, the specialisation dimension of Legitimation Code Theory (LCT) (Maton 2014:30-33) was drawn on to identify the specialist knowledge structures and knower dispositions in work-readiness training. The wide application of LCT in technical and vocational education is largely because of its usefulness and effectiveness in opening up knowledge, and knowledge practices and dispositions, to increasing numbers of teachers and students. While LCT has not been applied to a study of work-readiness training, its propensity to make the 'rules of the game' (Maton 2014:11) visible is central to this research study. The examples cited above provide evidence of the suitability and appropriateness of a framework such as LCT to explore concerns related to graduates' work-readiness.

The specialisation dimension of LCT explains what makes a programme and its participants worthy of distinction, and is based on the premise that 'practices and beliefs are about or oriented to something and made by someone' (Maton 2014:29). In some fields (such as in engineering), epistemic relations (ERs) are stronger, while in other vocational fields (such as Marketing), social relations (SRs) may be more dominant. Both ERs and SRs will be present in all fields; what is important is the relative strengths of their emphases. Thus, a claim to legitimacy can be viewed as specialised by its ERs, by its SRs, by both or by neither. Emphasis on the ER suggests that the possession of specialised knowledge, skills or procedures is important as the basis of achievement, while 
the social dispositions of the subjects, although not unimportant, are not central. On the other hand, an emphasis on SRs implies that technical knowledge or skills are less significant; instead, it is the dispositions of the subject as a knower, which is the measure of achievement. In some fields (in vocational education, these would be typified by the health sciences), possessing both specialist knowledge (e.g. anatomy and pharmacology) and being the right kind of knower (e.g. a caring practitioner) is important. Finally, there are fields (and these would typically be new or emerging fields, such as Web Design), where neither specialist knowledge nor specific dispositions have been found to characterise the programme.

The specialisation dimension of LCT can be represented as a Cartesian plane in which the Y-axis represents a continuum of stronger $(+)$ and weaker (-) ERs to practices and objects; while the $\mathrm{X}$-axis represents a continuum of stronger $(+)$ and weaker (-) SRs to practices and their subjects (Figure 1).

Together, the relative strengths of the ERs and SRs give rise to a series of specialisation codes that encapsulate the basis of legitimation and achievement in a particular field. Technical programmes are typified by 'knowledge codes' (ER+, SR-) where the object and method of study are strongly underpinned by scientific knowledge and the scientific method. Marketing or hospitality is typified by 'knower codes' (ER-, SR+), where legitimacy is derived from the unique attributes and dispositions of the knower. An elite code $(\mathrm{ER}+, \mathrm{SR}+)$ implies that both possessing specialist knowledge and being the right kind of knower is important. ('Elite' does not mean 'socially exclusive' but rather highlights the necessity of possessing both legitimate knowledge and legitimate dispositions.) Finally, a relativist code (ER-, SR-) suggests that neither specialist knowledge nor specific dispositions characterise the programme.

Specialisation has been commonly used to distinguish the particular characteristics of different disciplines and fields, but the lens of specialisation can also be focussed on a specific field - in this case technical and vocational education - for

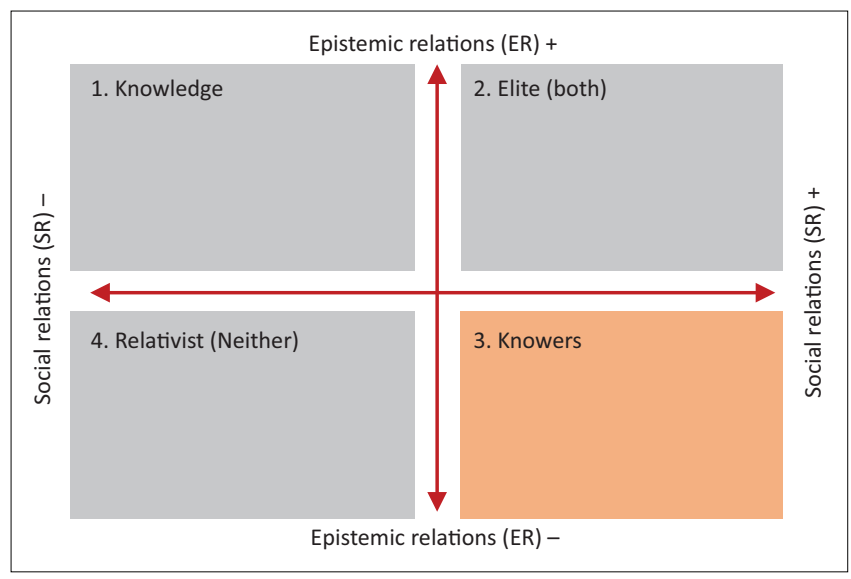

Source: Adapted from Maton, K., 2014, Knowledge and knowers: Towards a realist sociology of education, p. 30, Routledge, London

FIGURE 1: The specialisation plane. the purpose of uncovering both ERs and SRs in these fields. The particular configurations of the ERs and SRs in technical and vocational disciplines and fields will vary along a continuum, with many possible combinations and hybrids. The specialisation dimension renders visible a range of positions that academics and practitioners might see as legitimate forms of training in the field. Instead of forcing false dichotomies such as a technical field having only a 'knowledge code' and not having a 'knower code', specialisation makes visible the presence of both.

Most of the programmes offered by Universities of Technology would tend to cluster in the 'knowledge' quadrant of the specialisation plane (Quadrant 1 of Figure 2). Thus, they would be distinguished by stronger ERs $(\mathrm{ER}+)$ and weaker SRs (SR-) - always with exceptions to this general rule. Many of the business courses, such as marketing, public management and public relations, would have weaker ERs (ER-) and stronger SRs (SR+). A University of Technology does however tend to be typified by its strong technical programmes, such as the wide variety of engineering technician courses, courses in the applied sciences and business courses with a stronger ER, such as Accountancy and Internal Auditing. Work-readiness, because of its emphasis on personal and interpersonal skills, is located in the 'knower' quadrant (Quadrant 3 in Figure 2).

To address the issue of what kind of knowledge would typify work-ready knowers, it is necessary to develop a 'translation device' to address the 'discursive gap' between the high-level LCT concept and the application context (Maton \& Chen 2016:28). The review of the literature identified workreadiness to be largely located in the SR to knowledge; thus, work-readiness training intends to cultivate work-ready dispositions, rather than training involving disciplinary or field knowledge. It is to be expected that work-readiness training would therefore largely focus on strengthening SRs and building students as 'knowers', in this case building personal and interpersonal skills. Social relations to knowledge involve a re-orientation to the world of work.

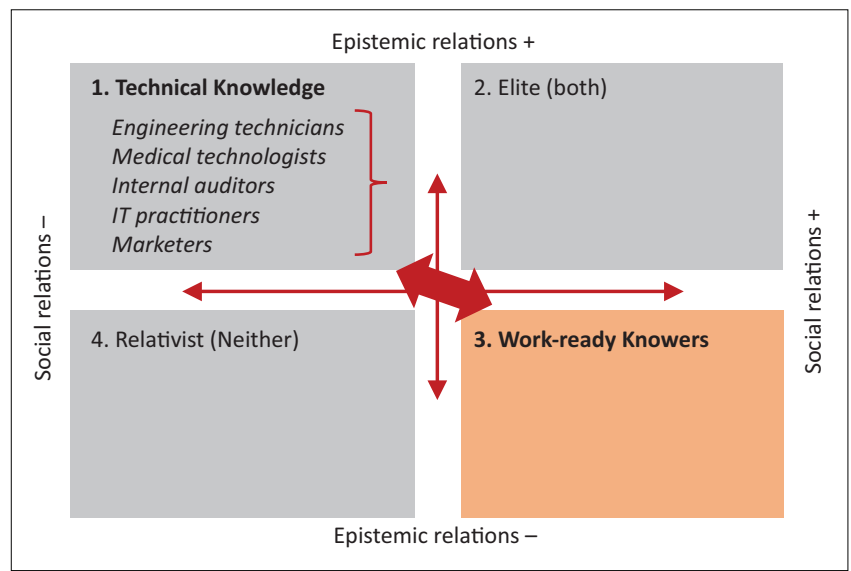

Source: Adapted from Maton, K., 2014, Knowledge and knowers: Towards a realist sociology of education, p. 30, Routledge, London

IT, information technology.

FIGURE 2: The specialisation plane in this study. 
In this world, ERs to knowledge matter less than SRs. In terms of work-readiness, SRs are exemplified by ideal knower's attributes that serve as a basis for professional identity within a field' (Maton 2014:32). Social relations are multiple, operate at different levels, are interconnected and develop cumulatively over time. Training a work-ready knower would thus involve an SR to the self (SR1), to others (SR2), to the workplace (company and/or industry) (SR3), to the profession (SR4) and to the broader society (SR5). These SRs could be identified along a continuum, as in Table 1.

Social relations might be similar or different across disciplines. For example, many practitioners may have similar aspirations to make broader social contributions (SR5), such as improving the quality of life in developing countries, but would have developed different understandings of how these might be achieved in their different disciplinary areas. Building a professional identity would involve an SR to the field or profession (SR4). While respect for others (SR3) would cut across many practices, the specifics of SRs to others in a workplace would be different - some might focus on managing others' work (e.g. in corporate environment), others might focus on patient care (e.g. in a clinical environment), while others might be part of a technical team (e.g. in an engineering company). A more generic version of SRs to others (SR2) would be the ability to get along with coworkers, to contribute to teamwork and to be supportive. Finally, there is an SR to the self (SR1), which involves building one's own values and ethical position.

\section{Evaluation research methodology}

The evaluation framework, developed from both the research literature and theoretical framework (Table 1), was used to assess the extent to which the EIP was able to strengthen SRs to the world of work. The research design comprised a 'theory-driven evaluation' (Chen 2006). In their classic study, Chen and Rossi (1980) pointed out that a major problem in programme evaluation is the adoption of 'conventional, common sense understandings of social problems and their

TABLE 1: The work-ready knower: Social relations in technical and vocationa education.

\begin{tabular}{|c|c|c|c|}
\hline Code & Description & LCT codes & $\begin{array}{l}\text { Stronger (SR+) or weaker (SR-) } \\
\text { social relations }\end{array}$ \\
\hline \multirow[t]{2}{*}{ SR5 } & \multirow{2}{*}{$\begin{array}{l}\text { Social relations to the } \\
\text { broader society }\end{array}$} & SR5+ & Stronger contribution to society. \\
\hline & & SR5- & Little or no societal contribution. \\
\hline \multirow[t]{2}{*}{ SR4 } & \multirow[t]{2}{*}{$\begin{array}{l}\text { Social relations to a } \\
\text { field or profession }\end{array}$} & SR4+ & $\begin{array}{l}\text { Stronger professional conduct } \\
\text { and identity. }\end{array}$ \\
\hline & & SR4- & $\begin{array}{l}\text { No or little attention to conduct, } \\
\text { etc. }\end{array}$ \\
\hline \multirow[t]{2}{*}{ SR3 } & \multirow[t]{2}{*}{$\begin{array}{l}\text { Social relations to a } \\
\text { company or industry }\end{array}$} & SR3+ & $\begin{array}{l}\text { Stronger contribution to the } \\
\text { workplace. }\end{array}$ \\
\hline & & SR3- & $\begin{array}{l}\text { Little or no contribution to a } \\
\text { workplace. }\end{array}$ \\
\hline \multirow[t]{2}{*}{ SR2 } & \multirow[t]{2}{*}{$\begin{array}{l}\text { Social relations to } \\
\text { others }\end{array}$} & $\mathrm{SR} 2+$ & $\begin{array}{l}\text { Stronger relationships with } \\
\text { others. }\end{array}$ \\
\hline & & SR2- & $\begin{array}{l}\text { Little or no attention relationships } \\
\text { with others. }\end{array}$ \\
\hline \multirow[t]{2}{*}{ SR1 } & \multirow{2}{*}{$\begin{array}{l}\text { Social relations to the } \\
\text { self }\end{array}$} & SR1+ & Stronger values and ethics. \\
\hline & & SR1- & $\begin{array}{l}\text { Little or no attention to values } \\
\text { or ethics. }\end{array}$ \\
\hline
\end{tabular}

LCT, Legitimation Code Theory; SR, social relation. treatments, without considering the appropriate social science theory' (67). Coryn et al. (2011), in a meta-analysis of theory-driven research, found that theoretical approaches were the key to designing rigorous evaluation projects.

For this study, a qualitative approach, including document study, observation, video ethnography and interviews, was followed. Video recording of the simulated production is an inherent feature of the EIP. The programme also allows the students to reflect on and improve their practice through repeated runs of the simulated production. During the pilot phase (2016-2018), full training sessions (i.e. including the theoretical sessions) of the chemical, electrical and mechanical engineering; information technology; office management and technology; as well as public management sessions were videographed for reporting purposes to the DHET and JICA. These videos as well as the reflective reports served as key data sources. It would be expected that the EIP would include a range of practices that are strongly underpinned by the principles of social interactions. This evaluation research study sought to reveal that the SRs were foregrounded or backgrounded, which codes tend to dominate in the EIP and what this might mean for the enhancement of students' work-readiness.

\section{Research sites}

The research sites included two higher educational institutions that offered EIP training, and 10 workplace sites. Each of the workplace sites accepted five (or more) interns, some of whom had completed the EIP and some of whom had not participated in the EIP. The two higher educational sites that were selected for this study were two Universities of Technology that implemented the EIP during the period 2016-2018. The two participating institutions are based in two different provinces of South Africa, have different 'profiles', but draw their students from similar socioeconomic backgrounds, and make use of similar workplaces for the training of their students. Only workplace sites with a minimum of five interns were included in the study.

\section{Participants}

The study population comprised four groups: (1) EIP students, (2) interns (both those who had completed the EIP training and those who had not attended the EIP), (3) EIP facilitators and (4) workplace supervisors. The first group comprised students who enrolled for EIP training between 2016 and 2018. The rationale for this group was to capture their more immediate perceptions of, and responses to, the EIP. The second group, the interns, were students who had been placed in workplaces by the institution's cooperative education department (or equivalent unit). The rationale for choosing interns who had undergone the training was to find out the extent to which they were able to transfer the skills that were taught in the training to a workplace. The rationale for the inclusion of interns who had not attended the EIP was to compare their responses and attitudes to the workplace. The third group of study participants comprised facilitators 
who conducted the training across 2016-2018. The rationale for their inclusion was to obtain both the South African and Japanese perspectives on the training. The fourth group of participants comprised the workplace supervisors who supervised and mentored interns over the period 2017-2018. The rationale for the selection of the supervisors was to include those who had had the opportunity to supervise a minimum of five interns, and compare the behaviours and attitudes of the EIP students against behaviours and attitudes of past student cohorts who had not had the same training. Purposive sampling (Miles \& Huberman 1994) was used to ensure that the participants had experienced the programme either as students, interns, workplace supervisors of student interns or facilitators in order to obtain first-hand information about the programme and its impact. The study sample included approximately 200 EIP students from the disciplines of chemical engineering, electrical engineering, mechanical engineering, information management, public management, as well as office management and technology, 50 interns, five facilitators (four South African and one Japanese facilitator) and 10 workplace supervisors.

\section{The research findings: Evaluating the Employability Improvement Programme against social relation codes}

The EIP is a 3-day training programme that includes an introductory theoretical element and hands-on practical sessions (with several iterations between the theory and practice, such as drawing on Kaizen concepts to reflect on practice). The hands-on practical sessions are the main focus of the training and require students to assume various roles as 'workers' in a simulated truck assembly plant. Through the work in this simulated plant, the students learn the implications of poor planning, inadequate problem-solving skills, poor inventory management, how to eliminate waste in the workplace and the consequences of poor teamwork and supervision. The concepts are taken from a world of work that has a focus on manufacture and production. The simulated production process is reduced and simplified to lessen the cognitive load (in LCT terms to weaken the ER) and enable a focus on the SR. The tasks allow the students to reflect on and improve their practice through repeated runs of the simulated production line. Each run is preceded by planning (drawing on the Kaizen tools) and ends with reflection towards improvement and innovation (drawing on Kaizen concepts). The theoretical content of the EIP is designed to enable students to develop and demonstrate their understanding through a series of short exercises. The theoretical content is presented in the form of PowerPoint slides on the first day of the programme, but these media resources are drawn on throughout the 3-day programme for reflection and planning. The students initially engage with the Kaizen concepts through exercises that are either scenarios given to students for group work or video clips of work activities that students analyse. Once the practical training starts, the Kaizen concepts become more fully integrated into practice.
The intended outcomes of the EIP are: (1) to understand lean manufacturing principles and how they can impact daily work; (2) to understand organisational roles; (3) to plan and organise work; (4) to identify and solve problems; (5) to manage time; (6) to work in teams; and (7) to identify and avoid waste. These outcomes can be broadly clustered into SRs to the self (SR1), such as the development of values and dispositions (e.g. lean principles, time management and eliminating waste), SRs to others (SR2), such as effective teamwork, and SRs to a company (SR3), such as understanding work processes and appreciating organisational roles. The core learning activities, intended to meet these outcomes, are clustered into four modules. Basic concepts were introduced and then applied in a production simulation game in which student teams were given materials to build simple model trucks over several iterations, each time attempting to improve on their processes and outputs. Lean terms and concepts, such as eliminating waste, were emphasised throughout the short course, supported by active learning exercises that helped the students to grasp these concepts. The modules had minimal theoretical content, but emphasised application and practice, always integrating previous concepts and actions. In the subsections below, the evaluation findings with regard to the five levels of SR to work-readiness are presented.

\section{Social relations to the self (SR1)}

The first module on 'productivity' foregrounded the SR to the self (SR1) and the SR to others (SR2), both which are strongly present in Kaizen principles. The key value that the training instilled in the students was the elimination of waste. The concept of waste elimination was introduced in order to help students reconceptualise 'waste' in an industry context. One of the 'Seven Wastes' is time wastage; thus, time management was an important personal skill taught on the EIP.

While viewing the video footage of their operation, the students were prompted to identify areas where time was wasted during their operation. Many students were able to identify time-wasting activities in their process, and understood how these impacted their ability to deliver the required number of trucks within the allocated time. In focus group interviews, many interns attributed their improved time management skills to their learning experiences on the EIP. A chemical engineering intern, showing that he had internalised the Kaizen principle, explained:

'In our company, we deal with optimisation a lot, meaning that I must establish what I could do to achieve the same result using less.' (Intern 7, Chemical Engineering graduate, male placed in water utility company)

The student refers to the company where he was placed as 'our' company, suggesting that he experienced a sense of belonging or identification with the company (in LCT terms strengthening the SR to the workplace (SR3) through practising the foundation Kaizen principle of eliminating waste). 


\section{Social relations to others (SR2)}

The second module on 'implementation' introduced teamwork using video clips to demonstrate the extent to which goals are achieved when individuals work together. The first production run began in Module 2. The simulated assembly plant and the tools and equipment that students used in the practical training were introduced. Teams and roles were allocated, and students started to assemble the 'trucks'. The teams in the simulated workspace were allocated a certain number of trucks to assemble within a specific time period, along with the specifications and parts' lists.

The intention was that students would learn from one another in their teams, and learn the value of cooperation and good communication in teamwork. Teamwork was embedded throughout the truck assembly operation, and it was intended that the students learn from their own experience as to how good teamwork enhanced productivity. The teams were required to work together as they planned their operation and assembled the trucks. Through reflection and constructive criticism of one another's actions, the students identified how working or not working as a team affected their productivity. In their reflections, students appreciated how the EIP had taught them 'to work with different people and to always be in one's best behaviour in the working environment' (Student 7). One of the engineering students linked the benefit directly to the engineering field:

'In Engineering they need a person that can work in a team and this course gives us practice in that regard.' (Student 10, EIP participant, male, mechanical engineering)

From the focus group interviews with interns and workplace supervisors, it seemed that the teamwork skills that they learnt on the EIP were, at least in some cases, transferred to the workplace. Through working in teams in the EIP, students were prepared for work environments in which they would need to communicate with diverse groups, and listen to their views. Chemical engineering interns at a water utility in Pietermaritzburg felt that the practice of working in teams on the EIP had helped them to 'adjust in the workplace and to work with different personalities' (Intern 8). An office management intern working at service department shared how her experience on the EIP had helped her deal with a peer who had made her feel unworthy of her internship:

'I eventually had realised that it was her personality and nothing wrong with me, and that just as we had learned in the EIP, there will always be different personalities in the work environment, mine is to find a way to work effectively with them.' (Intern 9, Office Management and Technology graduate, working in a service department)

In a focus group interview, a chemical engineering student felt that the teamwork on the EIP had taught her that 'everybody in a team has an opinion and that communication was key' (Intern 10). A mechanical engineering intern who was placed at a company in Richards Bay said that the EIP had helped him to develop the confidence to work in different teams:
'I work with five people in my team but we also work with other teams. So I am interacting with various teams and the EIP had helped me with the confidence to deal with these teams.' (Intern 11, Mechanical Engineering graduate, male working in a manufacturing company)

A workplace supervisor at the same company compared Intern 11 to one who had not undergone the EIP and said:

'I usually pair students with others from different institutions ... [Student 11] is quite forthcoming and manages team dynamics ... in contrast ... the other one from the same institution will wait to be coerced and struggles to work with the team.' (Workplace Supervisor 7, male; mechanical engineer working in a manufacturing company)

It also seemed from the interviews that the fact that the students in a team are further grouped into sub-teams to work on different areas on the truck assembly had had an unexpected outcome in that it had taught the students about benchmarking:

'When we did the training, we worked in small teams and when you were having a problem with a certain part assembly ... we identified a team that was not having a problem and studied what they were doing right ... this is the same here at work ... when we find that we are having a problem with a certain part we go to another department and use the information we get there to improve our work.' (Intern 12, mechanical engineering graduate, male, working in a manufacturing company)

Generally, there was agreement that the EIP had prepared the students for working with different people and, in contrast to their peers who had not undergone the EIP training, they had come into the workplace with a level of confidence.

\section{Social relations to a company or industry (SR3)}

The third module, 'improvement', delved more deeply into work processes: inputs, outputs, workflow, project cycles, productivity calculations, work breakdown structures and so on. The module also introduced some of the tools that students would use in the simulation. For example, students learnt problem identification and solving using the 'logic tree' as a tool. Planning and organising work was introduced in a contextualised way, as students initially started working without a clear plan. Learning the importance of planning and organising happened as they reflected on their actions.

The intention of the problem-based strategy was to guide students in the process of diagnosing a problem and implementing a solution. Through reflective practice and diagnosing problems in their operation, the students applied workflow concepts to their own practices (Figure 3). This process helped the students to develop improvement plans for subsequent runs of operation. Reflecting on problemsolving, an electrical engineering student reflected: 'I have learnt that in the workplace, I must try to solve a problem and not call the supervisor all the time' (Student 5); another wrote: 'I learnt to take initiative and attempt to solve a 


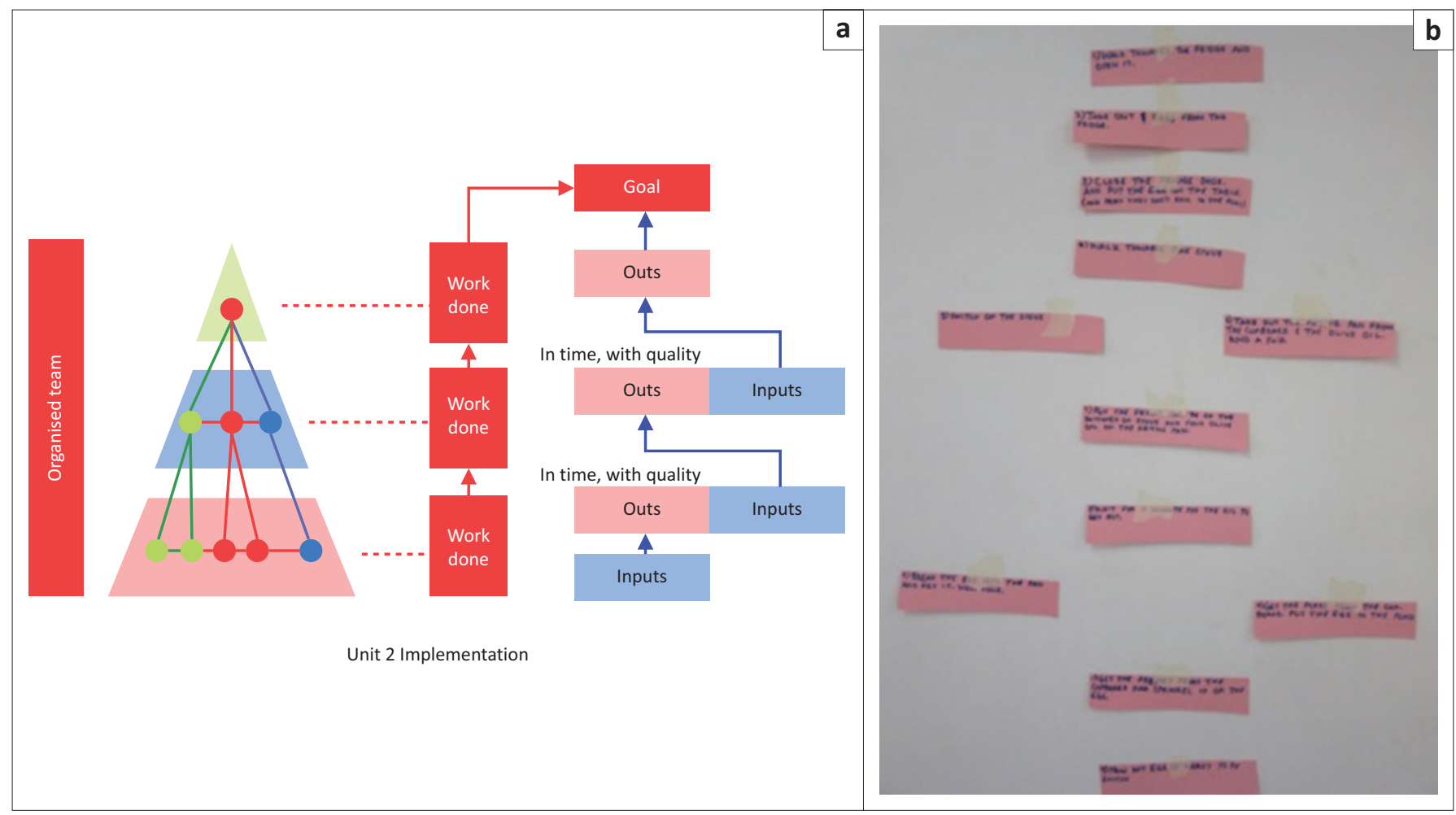

Source: (a) Japan International Cooperation Agency, 2016, Employability improvement Program: Unit 2, Implementation, slide 8, Unpublished course notes on 26 Feb. 2016; (b) photo taken by F. Nofemela.

Note: Employability Improvement Programme slide 8 and example of students' application of the logic tree.

FIGURE 3: Concepts into practice (a) PowerPoint slide depicting work done and team work (slide 8); (b) photograph of students' activity on workflow.

problem' (Student 6). The workplace supervisor of an office management intern commented:

'I noticed that the intern was able to attend to smaller issues without referring them to a senior ... for an example she would pick up why a claim would potentially not be payable and immediately contact the claimant ... this has helped us to reduce our turn-around times.' (Workplace supervisor 2, male, Accountant, working in a Finance department)

Sometimes, however, workplace supervisor 6's intern was not able to distinguish between what he could attend to and what he should refer to the supervisor:

'In the training ... perhaps there needs to be some emphasis on proactivity and decision making to be able to discern between what the intern can handle and what needs to be referred.' (Workplace supervisor 3, female, office manager in an operations department)

From the perspective of the interns, it seemed as though the application of workflow and other problem-solving skills depended on the readiness of the work environment to allow the intern space to act autonomously. This seemed to have been the case for a public management intern who was placed at a clinic and found that, as a junior intern, she did not have the confidence to suggest solutions to a problem. Another intern explained that although the reception had been good at his place of work, he had found in the first year that a:

' $[P]$ latform was not made available to make suggestions.' (Intern 5, female, Office Management and Technology graduate working in a clinic)
Although not addressing the issue of whether or not an intern had been granted a platform, a supervisor indicated that workplaces also need to be prepared for students and made to understand that interns are there to:

'[A]dd value and somehow reduce one's workload while learning.' (Workplace supervisor 5, female, office manager in a service department).

Workplace supervisor 8 agreed:

'Sometimes the mentors do not give the intern opportunity to grow ... they are somehow scared to give them responsibility and tend to treat them as if they are incapable of making decisions or they will make mistakes.' (Workplace supervisor 8, male, office manager in a procurement department)

Workplace supervisor 9 concurred, explaining that had he known about the EIP and what it teaches the student, he would have created more opportunities for the interns to demonstrate their capabilities. He suggested that host employers be given an orientation of the training programme as well.

\section{Social relations to a field or profession (SR4)}

In Module 4, 'innovation', students were introduced to the idea of innovation, in particular the Kaizen understanding of innovation as evolving through continuous improvement. The fourth module defined innovation for the students and provided its examples. It also showed archived videos of previous training sessions to illustrate how creativity could be brought into vehicle assembly. Innovation, in alignment with 
the Kaizen idea that innovation emerges from practices that follow Kaizen principles, was understood as part of the production run. Central to innovation in the EIP are the 'jigs' that were introduced for the purpose of improving work practices. Students were given the freedom to use whatever was in the room to improve their efficiency. The module encouraged the students to work together to conceptualise and test the 'jigs'. Following each run, and following reflection towards improvement, students actively engaged with one another to create and test the 'jig'. In the EIP, innovation is expected to emerge from teamwork, openness around the identification of errors, planning for improvement, working as a stronger team that is more aware of its own strengths and weakness and then innovating - seeing opportunities for potential and change. Innovation is not restricted to Module 4; it can happen whenever the teams innovate, but more activity is encouraged towards the end of the programme. Figure 4 shows how students used innovation to improve the workspace from an untidy space to an improved one.

The literature on lean education suggests that artefacts that are produced in the production runs (or other simulation) should be meaningful to the professional context, otherwise academically experienced faculty members may lack the confidence to approach the material (Murman et al. 2014). Given this assertion, it can be expected that the nonengineering students who had undergone the EIP would have found the use of the miniature trucks in the EIP problematic, particularly at the beginning of the training as they would find it difficult to make the connection between truck assembly and their own disciplines and fields. For example, an electrical engineering student felt that the truck was a mechanical engineering tool and as such was not suited to his discipline:

'Although I learnt to work in teams, I feel that this training is for Mechanical Engineering students and has no link with Electrical Engineering.' (Student 3, male, EIP participant, Electrical Engineering)

Similarly, during the interviews, a public management intern commented:

'When we were given the instructions to work on the truck, I could not understand how this relates to my qualification.' (Intern 1, male, public management graduate working in a maintenance department)
A chemical engineering intern commented:

'[The EIP] does not do much for me in industry as the environment is different. It might help to adapt it to other industries.' (Intern

2, male, chemical engineering graduate working in a water utility company)

Despite these views, the majority of the interns from chemistry, office management and technology, public management, and even most of the students from chemical engineering, were able to link the trucks and related tools to work processes more generally. For example, the majority of the chemical engineering interns indicated that they could link elements of the EIP, such as continuous improvement, housekeeping and so on, to plant optimisation in which they were required to improve processes in order to achieve the best result with less inputs. The management interns, in their focus group interviews, also said that they understood that the truck was merely a tool and of importance were the learning outcomes that prepared them for workplaces. They added that perhaps the use of an artefact that was unrelated to the field was exactly what was needed to create adaptability skills. A similar view was held by facilitators. An EIP facilitator in the health sciences suggested that limiting students' work-readiness training to their own field would not enhance students' readiness for life. Other EIP facilitators agreed, indicating that in their experience, the use of the trucks had not negatively affected students' learning but suggested a need for the facilitator to provide a 'rounding-off' of the training by providing space for the students to apply the concepts in their own field of study. An EIP facilitator claimed that while there was no need to use tools other than the trucks, she believed that the facilitator had to ensure that the students understood the purpose of the training at the beginning. She commented on her experience with offering the EIP training to nonengineering students:

'[Non engineering students] have this belief that engineering students are smarter and are therefore apprehensive of the use of trucks in the beginning, but once, as the facilitator, I lay the foundation by explaining that the truck is merely a teaching and learning tool and I explain the expected outcomes of the
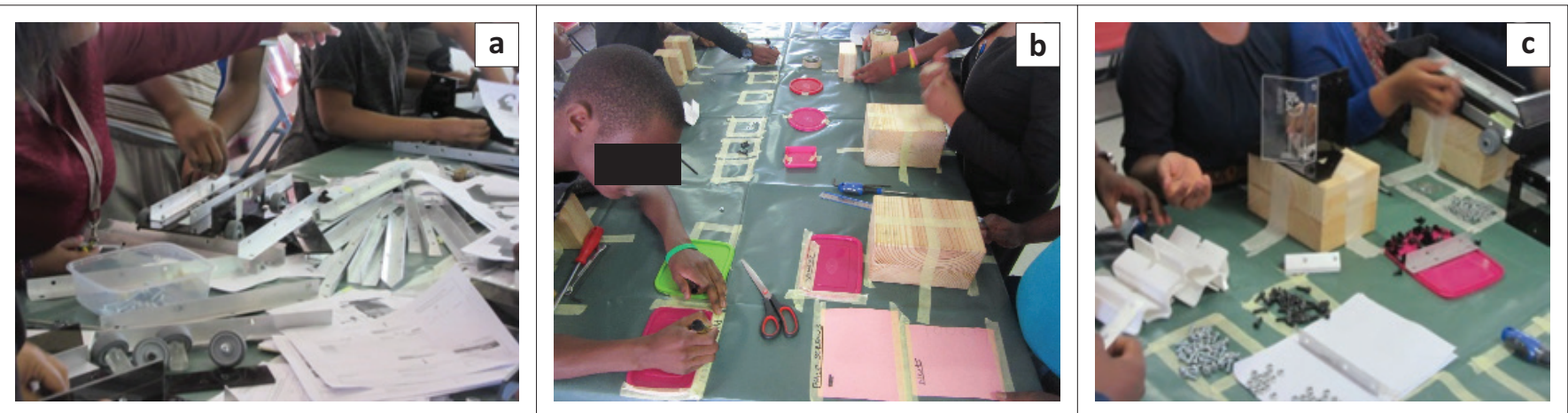

Source: Still images from video recording, taken by F. Nofemela

FIGURE 4: Improving the workspace: (a) students working at an untidy workspace; (b) students developing 'jigs' to tidy the workspace; (c) a much neater workspace as a result of improvements. 
training, they loosen up and achieve excellent learning.' (Facilitator 3, female facilitator, research site 2)

The facilitators felt that while there was no need to change the miniature truck as a teaching tool, the simulated environment could become more authentic by including different portfolios such as training and development as an element of human resources management, cost analysis as an element of finance, ergonomics as an element of environmental health and so on:

'All these different elements would give the student something close to a comprehensive picture of the workplace.' (Facilitator 3, male facilitator, research site 1 )

The facilitators suggested that the use of the trucks for nonengineering students could orientate the students towards being adaptable. Adaptability is the key work-readiness indicator (Caballero et al. 2011:45).

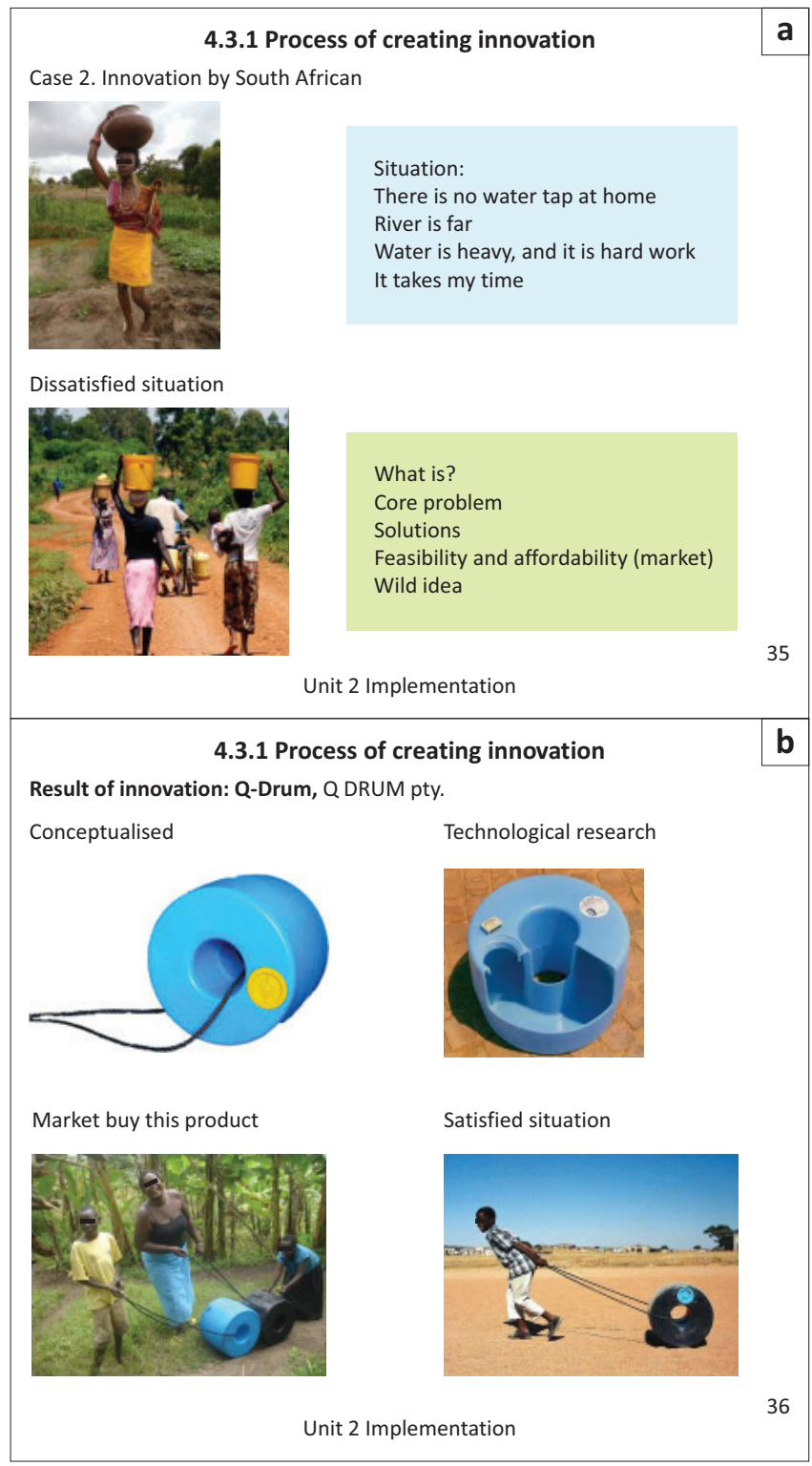

Source: Japan International Cooperation Agency, 2016, Employability improvement Program Unit 2, Implementation, slide 35 and 36, Unpublished course notes on 26 Feb. 2016

FIGURE 5: Process of creating innovation: (a) Rural women carrying water on their heads; (b) Q-drum as a solution for carrying water.

\section{Social relations to broader society (SR5)}

To encourage the students to think about innovation in the context of societal contribution, the case of the Q-Drum was presented. The Q-Drum was developed in South Africa and is an innovation designed to help rural women who carry water on their heads. The Q-Drum can be filled with water and then be pulled, instead of being carried on the head. The students were taken through the process of innovation from problem, conceptualisation, research and development, market research and finished product (Figure 5). As a group exercise, the students were encouraged to discuss possible further improvements to the Q-Drum.

The South African context did not feature strongly in the EIP. There was thus a missed opportunity to show how work leading to innovations, such as the Q-Drum, could benefit society beyond its benefit to the company that produced this product. There were many more examples taken from the Japanese context, particularly with regard to manufacture, in spite of there being many examples of Japanese factories in South Africa (Zondo 2018).

\section{Discussion}

The focus of the EIP is on SRs to the self (SR1) and to others (SR2). In spite of it being such a short course, the EIP made curricular space for considerable teamwork, for several iterations of the production runs and for reflective practice in the forms of debriefings after each production run. In the video clips of the practical training (from Modules 2 to 4 ), one can see the impact that the iterative pedagogy had on how students organised their workplaces more effectively (see Figure 4). While the EIP cannot be expected to meet multiple demands and requirements, and it might be unrealistic to expect the EIP to have achieved more than the strengthening of SRs to the self (SR1) and to others (SR2), there are notable gaps in the macro-level SRs (SR3, SR4 and SR5), as well as very obvious relevance to the South African context.

The most obviously missing element in the EIP - and which is strongly present in most examples of lean education towards work-readiness (Candido, Murman \& McManus 2007; Mansur, Leite \& Bastos 2017:28-29) - is a sense of the broader contribution that students will be able to make to their workplaces, their professions or even the national economy through their practice (SR5). In other words, the training needed a clearer sense of purpose and meaning. There are opportunities for Kaizen-based training 'to transcend the conventional applications of Lean' (Sawhney \& De Anda 2017:111). A strong part of students' motivation, across a wide range of disciplines, is that their education will allow them to improve the lives of others. This is particularly the case for South African students, many of whom are strongly driven by the need to 'make a difference' through their education (Nell 2014). The EIP has not been adapted for the South African University of Technology sector where the majority of students are from economically disadvantaged backgrounds, and where many of the qualifications offered 
by this sector are the key to South Africa's development (Wedekind \& Mutereko 2016). While going into depth on a particular contribution to the national economy would be beyond the scope of a short course, it is an oversight of the EIP not to make some attempt to contextualise workreadiness and the Kaizen concepts of respect for others' increased productivity and the elimination of waste in relation to larger national and local needs.

A second missing curricular element in the EIP is SRs to the field or profession (SR4). An SR to the field, in the form of an emerging professional identity, is difficult to achieve when the programme is as generic as the EIP. In many of the workreadiness programmes described in the literature, there is a clear adaption of the simulated production 'game', which tends to have a natural 'fit' with engineering disciplines (Alves et al. 2017), and to other disciplines and fields, such as avionics (Murman et al. 2014), health sciences (Sawhney \& De Anda 2016) or business sciences (Carenys \& Moya 2016). Key to the success of a lean short course for work-readiness is the alignment of its values with those of professional practice in different fields. Sawhney and De Anda (2016:103) explained that a work-readiness short course 'has to be in line with traditions and norms of the culture where the implementation is taking place' ... because that 'environment (with its cultural values) determine $[s]$ the success of the initiative'. It is also important that the artefacts that are produced in the production runs (or other simulation) are meaningful to the professional context, although simplified. In the aerospace short course, aeroplane parts are assembled (Murman et al. 2014); in the University of Tennessee's health sciences workreadiness short course, a hospital emergency reception ward is simulated (Sawhney \& De Anda 2016); and in an online business work-readiness course, there are virtual artefacts associated with office environments (Carenys \& Moya 2016). The reduction of high-level complex artefacts or machines (in the language of LCT, the reduction of the ERs) is a key feature of lean work-readiness short courses; this is performed to enable a focus on the multiple SRs in practice. However, the weakening of the ER should not involve complete decontextualisation, as this defeats the purpose of workreadiness training by making the social concepts and practices learnt considerably more difficult to transfer to relevant workplaces (De Vin, Jacobsson \& Odhe 2018).

The use of vehicle simulation in the South African EIP derives directly from the origins of lean production in the Toyota manufacturing plant. Motor manufacture has an extremely positive symbolic meaning in Japan, related to national pride in manufacture (Fujino \& Konno 2016). This is not the case in South Africa, where motor assembly has different symbolic meanings. The South African automotive industry includes a range of practitioners 'from very low-skilled manual labour to high-skilled engineering and management' (Wedekind \& Mutereko 2015: 22-23), with difficult employer relationships, and low levels of trust typifying work in the industry. The point is that vehicle parts are not neutral artefacts but are highly symbolically charged; in the South African context, this needs to be a consideration.

The above relates to the final missing curricular component of the EIP, that is, SRs to practices in organisations and companies (SR3). This is a key component in the South African context where labour relations are complex and difficult. In their report on South African industries, Wedekind and Mutereko (2015) found a recurring theme across case studies to be the issue of trust between parties and within the organisation. There is thus a lost opportunity in the EIP to use the Kaizen tools in order to make a contribution towards improved workplace relations. Simulations have proven to be beneficial in enabling participants from various backgrounds to meaningfully engage in learning from experience, and interactive simulations can play a role in improving relationships in a multi-stakeholder setting (Proches \& Bodhanya 2012). In spite of the EIP's stated outcome 'to understand organisational roles', this is only addressed in the theoretical training and not extended into the practical training - at least not to the same extent of, for example, teamwork in the production process. Thus, in terms of the SRs to organisations or companies, there is insufficient strengthening of the SRs. The evaluation criteria comprise five types of SRs: SRs to the broader society (SR5); SRs to a field or profession (SR4); SRs to a company or industry (SR3); SRs to others (SR2); and SRs to the self (SR1). While many studies of work-readiness training explain that intrapersonal and interpersonal skills are needed for work-readiness (e.g. Kaider, Hains-Wesson \& Young 2017:158-9; Mohamad et al. 2016:3401) and some studies are more specific with regard to lists or dimensions of interpersonal and intrapersonal competences and abilities (e.g. Caballero et al. 2011), this study has provided a theoretically consistent framework within which the many descriptions of skills and lists of attributes that have been empirically studied and reported on in the research literature could be theoretically located. The theoretical framework has thus provided an insight into the underpinning principles and logic of work-readiness training. Drawing on this framework enables a theorybased evaluation of programme in support of students' work-readiness. This was the intention of a realistic, theorybased evaluation of the EIP.

\section{Conclusion}

The knowledge contribution that the EIP curriculum evaluation makes is the development of a theory-driven evaluation instrument, which has an application beyond the EIP to a work-readiness programme in general. The research has shown that SRs to the wider society (SR5) are supported when examples from the local context are used. The use of foreign contexts and examples limits students' ability to develop SRs to the local social and economic context. Thus, local examples and local illustrations create meaning for students in ways in which foreign contexts and examples cannot achieve. 
Somewhere between the criticisms of Kaizen-based workreadiness training as 'instruments for the oppression of the workforce' (Sears 2003) and the praise heaped on them as courses where students 'learned more ... than [in] any course they had taken in college' (Murman 2017:vi) is a middle ground that recognises their shortcomings and acknowledges their potential. The shortcomings of the EIP have been pointed out in the evaluation process - in particular, the need for the EIP to take into account students' professional identification with the field of practice, the South African labour relations context and the greater societal contribution that can be made through the exercise of professional and ethical work practices. The strength of the EIP, which was shown in the evaluation, emanates from the nature of Kaizen itself: continuous improvement. Continuous improvement is translated into pedagogy as iteration towards improvement and innovation. This pedagogy is highly innovative - indeed academic departments might consider the use of iterative cycles towards improvement in student projects, for example. Such iterative pedagogies are unusual in higher education, where there is always a rush to complete the curriculum before the end of the academic year. Kaizen teaches a 'slow pedagogy' (Berg \& Seeber 2016) : the importance of planning and the time that this takes, and the importance of re-doing something, and re-doing it again, in order to make it better.

It is hoped that the recommendations arising from this study will be implemented in the spirit of Kaizen - continuous improvement towards innovation. As small changes are implemented across the EIP, it is hoped that it will become an effective programme in support of South African higher education students' work-readiness for the South African world of work.

\section{Acknowledgements}

The authors acknowledge the support of the students, interns, facilitators and workplace supervisors who were participants in this research project.

\section{Competing interests}

The authors declare that there are no conflicts of interest.

\section{Authors' contributions}

The first author undertook all the research activities; both authors contributed equally to the conceptualisation and the writing of this article.

\section{Ethical consideration}

Ethical clearance for the study was obtained from the Cape Peninsula University of Technology's Education Faculty Ethics Committee (Ethical Clearance Number: EFEC 3-9/2017).

\section{Funding information}

The research presented in this article was supported by the National Research Foundation South African Research Chair in Work-Integrated Learning (Grant Number 101889).

\section{Data availability statement}

The data for this article are available from the Cape Peninsula University of Technology Institutional Repository (http:// etd.cput.ac.za/).

\section{Disclaimer}

The views and opinions expressed in this article are those of the authors and not that of the National Research Foundation.

\section{References}

Ahmad, K., Zainal, N.F.A. \& Rahmat, M., 2012, 'Relationship between employability and graduates' skills', International Business Management 6(4), 440-445. https:// doi.org/10.3923/ibm.2012.440.445

Alves, A.C., Sousa, R., Dinis-Carvalho, J. \& Moreira, F-J., 2017, 'Lean education at University of Minho: Aligning and pulling the right requirements geared on competitive industries', in A.C. Alves, S. Flumerfelt \& F.-J. Kahlen (eds.), Lean education: An overview of current issues, pp. 149-176, Springer, Dordrecht.

Berg, M. \& Seeber, B.K., 2016, The Slow Professor: Challenging the culture of speed in the academy. University of Toronto Press, Toronto.

Caballero, C.L., Walker, A. \& Fuller-Tyszkiewicz, M., 2011, 'The Work Readiness Scale (WRS): Developing a measure to assess work readiness in college graduates', Journal of Teaching and Learning for Graduate Employability 2(2), 41-54. https:// doi.org/10.21153/jtlge2011vol2no1art552

Candido, J.P., Murman, E.M. \& McManus, H., 2007, 'Active learning strategies for teaching lean thinking', in Proceedings of the 3rd International CDIO Conference, MIT, Cambridge, MA, June 11-14, viewed 10 March 2020, from https://dspace. mit.edu/handle/1721.1/84441.

Carenys, J. \& Moya, S., 2016, 'Digital game-based learning in accounting and business education', Accounting Education 25(6), 598-565. https://doi.org/10.1080/09639 284.2016.1241951

Cavanagh, J., Burston, M., Southcombe, A. \& Bartram, T., 2015, 'Contributing to a graduate-centred understanding of work readiness: An exploratory study of Australian undergraduate students' perceptions of their employability', The International Journal of Management Education 13(3), 278-288. https://doi. org/10.1016/j.ijme.2015.07.002

Chan, W.K., 2015, 'Higher education and graduate employment in China: Challenges for sustainable development', Higher Education Policy 28(1), 35-53. https://doi. org/10.1057/hep.2014.29

Chen, H.T., 2006, 'A theory-driven evaluation perspective on mixed methods research', Research in the Schools 13(1), 75-83.

Chen, H.T. \& Rossi, P.H., 1980, 'The multi-goal, theory-driven approach to evaluation: A model linking basic and applied social science', Social Forces 59(1), 106-122. https://doi.org/10.2307/2577835

Coryn, C.L., Noakes, L.A., Westine, C.D. \& Schröter, D.C., 2011, 'A systematic review of theory-driven evaluation practice from 1990 to 2009', American journal of Evaluation 32(2), 199-226. https://doi.org/10.1177/1098214010389321

De Vin, L.J., Jacobsson, L. \& Odhe, J., 2018, 'Game-based lean production training of university students and industrial employees', Procedia Manufacturing 25, 578-585. https://doi.org/10.1016/j.promfg.2018.06.098

Fongwa, S., Marshall, D. \& Case, J., 2018, 'Exploring differences in South African graduate outcomes', in P. Aswin \& J. Case (eds.), Higher education pathways: South African undergraduate education and the public good, pp. 245-259, African Minds, Cape Town

Fujino, N. \& Konno, Y., 2016, Industry 4.0 and significance for Japanese Manufacturing, Nomura Research Institute, NRI Paper 210, viewed 08 July 2019, from https://pdfs.semanticscholar.org/c56e/65999799c67f3bf740b9a5dde7 ee63804889.pdf.

Japan International Cooperation Agency, 2016, Employability improvement Program: Unit 2, Implementation, Unpublished course notes on 26 February 2016.

Japanese Ministry of Internal Affairs and Communications, 2019, Statistics, viewed 10 March 2020, from http://www.stat.go.jp/english/

Jordaan, B. \& Cillié, G., 2016, 'Building a collaborative workplace culture: A South African perspective', in P. Elgoibar, M. Euwema \& L. Munduate (eds.), Building trust and constructive conflict management in organizations, industrial relations \& conflict management, pp. 1-13 Springer, Dordrecht, NL. 
Kaider, F., Hains-Wesson, R. \& Young, K., 2017, 'Practical typology of authentic workintegrated learning activities and assessments', Asia-Pacific Journal of Cooperative Education 18(2), 153-165.

Knight, P.T. \& Yorke, M., 2003, 'Employability and good learning in higher education', Teaching in Higher Education 8(1), 3-16. https://doi.org/10.1080/135625 1032000052294

Kraak, A., 2015, 'The value of graduate destination survey data in understanding graduate unemployment: A focus on the universities of technology', South African Journal of Labour Relations 39(1), 93-113.

Mansur, A.F.U., Leite, F.C. \& Bastos, H.P.P., 2017, 'Lean Education for Applied Science Universities: A proposal by Federal Institutes of Applied Sciences in Brazil', In AC, Alves, S. Flumerfelt \& F-J. Kahlen (eds), Lean education: An overview of current issues, pp. 24-40, Springer, Dordrecht, NL.

Maton, K., 2014, Knowledge and knowers: Towards a realist sociology of education Routledge, London.

Maton, K. \& Chen, R.T.H., 2016, 'LCT in qualitative research: Creating a translation device for studying contructivist pedagogy', in K. Maton, S. Hood \& S. Shay (eds.), Knowledge building: Educational studies in legitmation code theory, pp. 27-48, Routledge, London.

Miles, M.B. \& Huberman, M., 1994, Qualitative data analysis: An expanded sourcebook, Sage, London.

Mohamad, E., Ibrahim, M.A., Shibghatullah, A.S., Rahman, M.A.A., Sulaiman, M.A. Rahman, A.A.A. et al., 2016, 'A simulation-based approach for lean manufacturing tools implementation: A review', Journal of Engineering and Applied Sciences 11(5), 3400-3406.

Moleke, P., 2005, Inequalities in higher education and the structure of the labour market, HSRC Press, Cape Town.

Murman, E.M., McManus, H. \& Weigel, A.L., 2014, 'The LAl lean academy experience: Introductory lean curriculum', Journal of Enterprise Transformation 4(3), 205-225. https://doi.org/10.1080/19488289.2014.930543

Murman, E.M., 2017, 'Foreword', In A.C. Alves, S. Flumerfelt \& F-J. Kahlen (eds), Lean Education: An overview of current issues, pp. i-xiii Springer, Dordrecht, NL.

Nell, W., 2014, 'Sources of life meaning among South African university students', Journal of Psychology in Africa 24(1), 82-91. https://doi.org/10.1080/14330237.2 014.904087

Proches, C.N. \& Bodhanya, S., 2012, 'Interactive simulations for promoting transdisciplinary Understanding: A case study of the Western Cape fisheries, South Africa', The Journal for Transdisciplinary Research in Southern Africa 8(1) 17-29.

Raftopoulos, M., Coetzee, S. \& Visser, D., 2009, 'Work-readiness skills in the fasse sector', SA Journal of Human Resource Management 7(1), 1-8. https://doi.org/ 10.4102/sajhrm.v7i1.196
Rosenberg, S., Heimler, R. \& Morote, E.S., 2012, 'Basic employability skills: A triangular design approach', Education+Training 54(1), 7-20. https://doi.org/10.1108/ design approach,
00400911211198869

Sawhney, R.S. \& De Anda, E.M., 2017, 'Lean educational maturity model at the University of Tennessee', in A.C. Alves, S. Flumerfelt \& F.-J. Kahlen (eds.), Lean education: An overview of current issues, pp. 99-124, Springer, Dordrecht, NL.

Sears, A., 2003, Retooling the mind factory: Education in a lean state, University of Toronto Press, Toronto, ON.

Shay, S. \& Steyn, D., 2015, 'Enabling knowledge progression in vocational curricula: Design as a case study', in K. Maton, S. Hood \& S. Shay (eds.), Knowledge-building, pp. 156-175, Routledge, London.

Smith, E.E. \& Krüger, J., 2008, 'A critical assessment of the perceptions of potentia graduates regarding their generic skills level: An exploratory study', South African Journal of Economic and Management Sciences 11(2), 121-138. https://doi. org/10.4102/sajems.v11i2.304

Statistics South Africa, 2019, Economic growth, viewed 10 March 2020, from http:// www.statssa.gov.za/.

Stone, K.B., 2012, 'Four decades of lean: A systematic literature review', International JournalofLeanSixSigma3(2),112-132.https://doi.org/10.1108/20401461211243702

Tomlinson, M., 2017, 'Forms of graduate capital and their relationship to graduate employability', Education+Training 59(4), 338-352. https://doi.org/10.1108/ET05-2016-0090

Van Broekhuizen, H., 2016, Graduate unemployment and higher education institutions in South Africa, Bureau for Economic Research and Stellenbosch Economic Working Paper 08, 16, viewed 08 July 2019, from http://www.sun.ac.za.

Van Dyk, G., 2015, 'Hardiness as predictor of work readiness: A preliminary exploratory study', Journal of Psychology in Africa 25(1), 80-82. https://doi.org/10.1080/143 30237.2014.997031

Vidal, M., 2007, 'Lean production, worker empowerment, and job satisfaction: A qualitative analysis and critique', Critical Sociology 33(1-2), 247-278. https:// doi.org/10.1163/156916307X168656

Walker, A., Yong, M., Pang, L., Fullarton, C., Costa, B. \& Dunning, A.T., 2013, 'Work readiness of graduate health professionals', Nurse Education Today 33(2), 116-122. https://doi.org/10.1016/j.nedt.2012.01.007

Wedekind, V. \& Mutereko, S., 2016, Employability and curriculum responsiveness in post-school education and training, HSRC Labour Market Intelligence Report 22, viewed 09 July 2019, from http://www.Imip.org.za/sites/default/files/ Report 22, viewed 09 July 2019, from http://WWW.Im
documentfiles//LMIP\%20Report $\% 2022 \% 20$ WEB.pdf

Zondo, R.W.D., 2018, 'The appropriateness of the design of experiments to support lean six sigma for variability reduction', The Journal for Transdisciplinary Research in Southern Africa 14(1), 1-6. https://doi.org/10.4102/td.v14i1.469 